\title{
Recomendações para aplicação da tipografia no contexto da baixa visão: uma avaliação com usuários
}

\author{
Recommendations for applying typography in low vision context: \\ an evaluation with users
}

Maíra Woloszyn, Mary Vonni Meürer

tipografia, legibilidade, leiturabilidade, baixa visão, mídias digitais

\begin{abstract}
Observar recomendações sobre legibilidade e leiturabilidade é fundamental para garantir a acessibilidade da informação para os leitores com baixa visão. Neste contexto, foi realizada uma revisão bibliográfica sobre essas recomendações a fim de abranger tanto estudos que tratam da legibilidade para todos os públicos, no meio impresso e digital e estudos focados no público com baixa visão. A partir da síntese destas recomendações foram feitas adaptações em um informativo sobre a Covid-19. As peças gráficas em formato digital foram enviadas a 3 pessoas com baixa visão que por meio de entrevistas semiestruturadas apresentaram suas considerações a respeito da experiência de leitura. Ao explanar sobre as peças, os participantes foram unânimes na preferência pela peça adaptada, destacando que os textos são mais confortáveis para a leitura. Analisando o resultado das entrevistas e a revisão bibliográfica confirmou-se a efetividade da maioria das recomendações encontradas na literatura.
\end{abstract}

tipography, legibility, readability, low vision, digital media

Due to the recognition of recommendations on legibility and readability, it is essential to ensure information accessibility for readers with low vision. In this context, we carried out a bibliographic review on these recommendations to cover: (I) researches that deals with legibility for all audiences in print and digital media and (II) researches focused on the public with low vision. From the synthesis of these recommendations, we purpose adaptations to a newsletter about Covid-19. We sent the graphic pieces in digital format to 3 people with low vision who, through semi-structured interviews, presented their considerations regarding the reading experience. When explaining the pieces, participants were unanimous in their preference for the adapted piece, highlighting that texts are more comfortable for reading. Analyzing interviews and literature review results, we confirmed the effectiveness of most of the recommendations found in the literature.

\section{Introdução}

A popularização da internet e dos dispositivos móveis proporcionou o surgimento de uma nova fase para a sociedade da informação com diferentes formas de comunicação (Lemos, 2018). Com a difusão das mídias digitais, elas passaram a ser utilizadas em diversos contextos, como entretenimento, educação, entre outros. Assim, com a junção da informática, das telecomunicações e do entretenimento, o conteúdo apresentado ao usuário se tornou dinâmico, podendo integrar imagem, texto, vídeo, animação e áudio (Ribeiro, 2012). Portanto, destaca-se

Anais do $10^{\circ} \mathrm{CIDI}$ e $10^{\circ} \mathrm{CONGIC}$

Kelli C.A.S. Smythe, Rafael de Castro Andrade (orgs.)

Sociedade Brasileira de Design da Informação - SBDI

Curitiba | Brasil | 2021
Proceedings of the $10^{\text {th }} \mathrm{CIDI}$ and $10^{\text {th }}$ CONGIC

Kelli C.A.S. Smythe, Rafael de Castro Andrade (orgs.)

Sociedade Brasileira de Design da Informação - SBDI Curitiba | Brazil | 2021 
que os diferentes sentidos humanos são utilizados para interagir com as informações e é diante das características de cada indivíduo que a recepção e transmissão de informações pode acontecer de forma limitada ou não (Trevisan, 2012).

Dentre os diferentes elementos de mídia utilizados para apresentar as informações, verificase que o texto é um elemento chave das publicações. Salaverría $(2014$, p.33) destaca que o texto "é a coluna vertebral que sustenta e estrutura as peças informativas" mesmo em meio digital. Ribeiro (2012) ressalta que o texto é o elemento mais utilizado para transmitir informações. Também, para Pamental (2014), o texto é o elemento que cobre a maior parte de publicações digitais e web sites, sendo responsável por $90 \%$ do conteúdo visível na tela.

Responsável por compor e configurar textos, a tipografia pode ser definida como a área do design que estuda história, prática e processo de criação e aplicação de símbolos ortográficos e para-ortográficos (Farias, 2013). Para Scaglione (2014, p.19) "a tipografia cumpre papel central no design gráfico. A maioria das peças de comunicação gráfica exigem, em maior ou menor grau, o uso da palavra escrita para cumprir sua função, e da tipografia para sistematizar a escrita".

Com o objetivo de planejar e organizar o conteúdo e as informações, o Design de Informação promove a clareza da comunicação (Pettersson, 2012). Por isso, as mensagens devem ser devidamente concebidas, produzidas e distribuídas, e mais tarde, interpretadas corretamente e compreendidas pela maioria do público de destino. Portanto, é necessário considerar o usuário, ou leitor, nesse processo, bem como as suas potencialidades e limitações (Frascara, 2015).

Tendo em vista o alto uso das comunicações escritas e visuais, cabe destacar que as deficiências visuais podem ser limitadoras na percepção das informações. Conforme o IBGE (2010), no último censo realizado, mais de 6,5 milhões de brasileiros têm algum tipo de deficiência visual. Destes, 528.624 são cegos, ou seja, incapazes de enxergar, enquanto 6.056.654 pessoas possuem baixa visão ou visão subnormal, portanto, têm grande dificuldade permanente de enxergar. A baixa visão, ou visão subnormal, é definida pelo Conselho Brasileiro de Oftalmologia, com base na Organização Mundial de Saúde, como acuidade visual inferior a 20/60 ou um campo visual inferior a 10 graus de campo visual central, mesmo com a melhor correção visual disponível (Ottaiano et al., 2019). Alguns problemas relacionados à baixa visão são: degeneração macular, glaucoma, retinopatia diabética e catarata.

Apesar de ter aptidões visuais diferentes daqueles com visão considerada normal, os indivíduos com baixa visão possuem capacidade para ler e utilizar interfaces gráficas. Para tanto, alguns critérios na criação das mesmas devem ser revistos observando as dificuldades encontradas por esses usuários (Kulpa, Pozzi, 2010). Diante do exposto, o presente trabalho tem por objetivo avaliar a eficiência da aplicação das recomendações sobre tipografia para baixa visão em meio digital. Para tanto, propõe a realização de entrevistas com pessoas com baixa visão a fim de verificar a consistência de uma peça gráfica ajustada conforme as diretrizes encontradas da literatura sobre o assunto. 


\section{Recomendações sobre tipografia no meio impresso e digital}

A aplicação da tipografia em meios digitais é orientada por diferentes fatores. Considerando as particularidades das mídias e dos ambientes virtuais, Woloszyn (2018) propõe quatro dimensões de aplicação da tipografia em livros digitais, a saber: formal, de composição, técnica e tecnológica. A dimensão técnica trata de aspectos relacionados diretamente às famílias tipográficas aplicadas nas páginas digitais sendo eles a flexibilidade, que se refere à versatilidade dos tipos quando aplicadas em diferentes funções do texto, tamanhos e peso, e a adaptabilidade, que está relacionada à otimização da fonte para leitura em tela e boa visualização em diferentes dispositivos e sistemas operacionais. A dimensão tecnológica reúne aspectos que envolvem procedimentos e ações relacionados a tipografia visto que os tipos usados em meios digitais podem orientar as interações e a leitura a partir de elementos textuais de navegação como links, botões e tags, e também serem aplicados como affordance. Já as dimensões formal e de composição refletem questões relacionadas às formas das letras, suas variações bem como a relação com demais elementos presentes na página. Sendo assim, tratam também da legibilidade e leiturabilidade da tipografia, fatores essenciais para garantir que o usuário identifique com clareza e compreenda a informação textual exposta (Woloszyn, 2018).

Assim, cabe destacar que legibilidade é o termo usado para se referir à clareza de caracteres isolados e à percepção das letras por parte dos usuários. Sua medida é a velocidade com que um caractere pode ser reconhecido. Já a leiturabilidade está ligada à qualidade do conforto visual durante a leitura do texto como um todo e refere-se à compreensão da informação. Sua medida pode ser entendida como a quantidade de tempo que um leitor pode dedicar a um segmento de texto sem se cansar (Fontoura, Fukushima, 2012).

Para Kuzu e Ceylan (2010) a legibilidade e a leiturabilidade são os critérios mais importantes na aplicação da tipografia para garantir que as mensagens sejam transmitidas aos usuários de forma eficiente e rápida. Além disso, influenciam na interação do leitor com o texto e são apontadas em pesquisas como fatores que afetam as preferências de leitura pelos leitores (Tarasov et al., 2015; Mengtsunga et al., 2013).

Segundo Fontoura e Fukushima (2012) são diversos os fatores que condicionam a legibilidade. Um deles é o desenho da letra, visto que tipos com as proporções clássicas romanas, sendo estas com ou sem serifa, são os mais indicados para os textos longos devido a familiaridade dos leitores com esta proporção. Também, o espacejamento entre as letras deve ter um controle preciso e estes espaços tendem a ser maiores quando os tipos são aplicados em tela. Os autores ainda reforçam que o tamanho das letras deve considerar as necessidades do público que se destina as informações e que para a largura dos parágrafos se recomenda o uso de 45 a 65 caracteres por linha. Esses dois últimos fatores irão influenciar no tamanho das entrelinhas que devem ser proporcionais ao tamanho do corpo do texto e do comprimento da linha. Ainda, é reforçado que o desenho dos tipos deve ser adequado ao suporte de reprodução. Com base nestes fatores Fontoura e Fukushima (2012) definem 20 regras básicas da boa legibilidade, a saber: 
- Usar tipos clássicos, amplamente testados e experimentados.

- Evitar o uso de caixa alta pois dificulta a leitura.

- Usar o peso intermediário da família tipográfica, nem muito leve nem muito pesado.

- Usar a largura intermediária, evitando fontes condensadas ou estendidas.

- Manter um espaçamento entre as letras que garanta uma textura constante no bloco texto.

- Definir um comprimento de linha adequado pois linhas muito estreitas ou mundo largas comprometem o processo de leitura.

- Usar espaço entre as palavras menor que a entrelinha.

- Usar entrelinhas que facilitem a identificação da linha seguinte.

- Dar preferência ao alinhamento à esquerda.

- Criar um ritmo constante e atraente no bloco de texto.

- Indicar claramente os inícios de parágrafo.

- Evitar as janelas e palavras viúvas ou órfãs.

- Destacar palavras no texto com discrição, evitando atrapalhar o fluxo de leitura.

- Evitar deformações nas letras.

- Alinhar o texto pela linha de base, horizontalmente, da esquerda para a direita.

Tratando especificamente do meio digital, Woloszyn (2018) afirma que o tamanho da letra, cor e brilho relacionam-se diretamente com a legibilidade. Quanto ao tamanho da letra, a autora destaca que as fontes aplicadas em meios digitais costumam ser maiores que $o$ tamanho indicado para meios impressos devido a luminosidade do dispositivo digital que pode tornar as letras imprecisas. Por sua vez, com relação a cor, é preferível não utilizar muitas cores para os textos digitais, visto que o contraste, que quando moderado auxilia a não tornar a leitura cansativa. Além disso, o uso do brilho moderado do dispositivo favorece a leitura.

Já quanto a leiturabilidade, Woloszyn (2018) associa os espaçamentos e o comprimento da linha. Sendo assim, a autora afirma que os espaços entre letras e palavras são essenciais para a uniformidade dos textos e para facilitar a leitura e compreensão de informações. Os espaços entrelinhas conferem velocidade à leitura, portanto, indica-se o uso de entrelinha positiva, ou seja, com tamanho maior do que o do corpo do texto, cuidando para não ser muito exagerada. O comprimento da linha, ou largura de coluna, também interfere no conforto de leitura para o usuário. Seu tamanho irá variar conforme o tamanho da letra e os espaçamentos entre letras e palavras (Woloszyn, 2018).

Tendo em vista que os demais elementos da página também interferem na legibilidade e leiturabilidade dos textos, a dimensão de composição proposta por Woloszyn (2018) apresenta dois fatores relacionados entre si, a hierarquia e a relação do texto com as demais mídias presentes na página. Para a autora, a hierarquia é essencial para organizar o conteúdo e conduzir o leitor pelas informações. Para identificar os diferentes conteúdos é proposto o uso de variações tipográficas de peso, estilo, tamanho ou família tipográfica. Normalmente, as variações negrito e itálico são utilizadas para dar destaque em meio a um fluxo de texto composto com tipos romanos. Inverter essa ordem, poderá causar desconforto ao leitor. Ainda, 
é preciso considerar como a tipografia se integra com os outros elementos presentes na interface digital como imagens, fundos, vídeos, etc.

As recomendações apresentadas por Fontoura e Fukushima (2012) e Woloszyn (2018) tratam de legibilidade de forma ampla, sem especificar o público com baixa visão. Os autores apresentados a seguir abordam recomendações semelhantes tendo como foco esse público.

\section{Legibilidade e leiturabilidade considerando o público com baixa visão}

Com a finalidade de identificar a percepção do indivíduo com baixa visão sobre a legibilidade de diferentes estilos tipográficos foi realizado um estudo com 3 estudantes de graduação e pós-graduação da Universidade Federal de Santa Catarina que apresentavam esta deficiência. (Meürer, Gonçalves e Correa, 2014).

$\mathrm{Na}$ ocasião, as participantes observaram na tela do computador um documento com 6 fontes diferentes aplicadas a um parágrafo e em tamanhos que variavam de 12 a 21 pt. As fontes utilizadas foram a Arial, Arial Italic, Times New Roman, Impact, Brush Script e Chalkduster. Com esta variedade de fontes buscou-se identificar como o desenho dos tipos, considerando suas proporções, texturas e estilo poderiam influenciar na leitura.

O resultado da pesquisa apontou as fontes Arial e Times New Roman como mais legíveis na percepção das participantes. Independente das fontes nomeadas, foi possível perceber que as características mais relevantes para uma boa legibilidade foram o desenho simples, sem ornamentos, proporções clássicas, peso regular e sem inclinação. A presença ou não de serifas não foi considerada como um ponto fundamental. Uma questão considerada de grande importância pelas participantes foi o contraste entre o texto e o fundo. Segundo elas, o contraste deveria ser acentuado, mas sem cores muito vibrantes. Quanto ao tamanho, nenhuma das participantes considerou boa a leitura abaixo de 18 pt. sendo apontado 0 tamanho 21 pt como mais confortável. Para uma das participantes, com nível mais severo de baixa visão, foi necessário ampliar o arquivo com lupa em $600 \%$, mesmo no corpo 21 pt.

Arditi (2014) em uma publicação não-acadêmica em parceria com a organização Lighthouse, propõe que a baixa visão dificulta a leitura pois reduz a quantidade de luz que entra no olho do leitor e desfoca a imagem retinal, reduzindo o contraste efetivo do texto, além de danificar a porção de retina mais adequada para a leitura, que prejudica a capacidade de ver letras pequenas e de fazer movimentos oculares que são cruciais para a leitura. para isso, apresenta 10 diretrizes para tornar os textos impressos mais legíveis para o público de baixa visão, são elas:

- O contraste entre o texto e o fundo deve ser alto;

- O uso de cores nos textos é orientado apenas em títulos e destaques, devendo-se priorizar o preto sobre fundo branco para o corpo dos textos mais longos;

- Recomenda-se utilizar fontes entre 16 e 18 pontos, porém observando que o tamanho varia de acordo com o desenho da fonte; 
- Com relação a entrelinha, orienta-se a aplicação de 25 a 30\% maior que o corpo do texto, garantindo assim um espaço facilmente perceptível entre o topo e a base do texto;

- Afirma-se que fontes com desenhos mais simples são melhor visualizadas, podendo ser com serifa ou não. Portanto, orienta-se evitar fontes decorativas ou condensadas;

- A escrita em caixa alta e baixa é mais legível. Portanto, deve-se evitar o uso do texto em itálico, pois dificulta a leitura;

- O espacejamento da fonte, distância entre os caracteres, deve ser perceptível, evitando que as letras pareçam juntas. Entende-se que as fontes mono espaçadas, com o mesmo espaço entre todos os caracteres, podem ser mais adequadas para leitores com baixa-visão;

- Recomenda-se o uso de margens internas largas, principalmente se a publicação for encadernação com lombada quadrada, pois facilita o manuseio da peça e o uso de dispositivos para ampliar o texto como os vídeo-ampliadores;

- Sugere-se o uso de papéis com acabamento fosco preferencialmente;

- Recomenda-se distinguir as publicações de uma mesma coleção por meio de cores e formatos, facilitando a identificação pelo usuário com baixa visão.

Semelhantemente, o Instituto Benjamim Constant (2014) também propõe algumas recomendações para produção de material didático para pessoas com baixa visão que se referem diretamente à tipografia. Conforme a instituição, deve-se priorizar os tipos de letra Arial, Verdana ou Tahoma na composição de textos para o público de baixa visão, evitando utilizar letras rebuscadas ou com serifas. Ainda, é indicado a aplicação dos tipos em um corpo de letra com tamanho de $24 p t s$ e em negrito. Já em relação a largura da coluna, conforme as indicações do Instituto Benjamim Constant (2014), o número de caracteres por linha não deve ultrapassar 39.

Propondo requisitos de projeto de interfaces gráficas de objetos de aprendizagem acessíveis para usuários com baixa visão, Pinto, Silva e Teixeira (2019) apresentam 19 requisitos. Dentre os que possuem relação com a tipografia, destaca-me os seguintes:

- Apresentar cores contrastantes;

- Evitar imagens de fundo

- Possibilitar a alteração das cores e tamanho do texto;

- Apresentar layout em coluna, bem organizado e bem definido;

- Apresentar conteúdo estático

- Possibilitar visualização monocromática

- Apresentar fonte legível

- Apresentar formatação adequada dos parágrafos de texto

Com base nas referências consultadas, construiu-se o quadro 1 a fim de comparar e sintetizar as orientações para tipografia digital voltada para usuários com baixa visão. 
Quadro 1: Diretrizes sobre a aplicação da tipografia para usuários de baixa visão e em meios digitais

\begin{tabular}{|c|c|c|c|c|c|c|}
\hline & $\begin{array}{l}\text { Pinto, } \\
\text { Silveira, } \\
\text { Teixeira } \\
\text { (2019) }\end{array}$ & $\begin{array}{l}\text { Instituto } \\
\text { Benjamin } \\
\text { Constat } \\
\text { (2014) }\end{array}$ & $\begin{array}{l}\text { Meürer, } \\
\text { Gonçalves, } \\
\text { Correia } \\
\text { (2014) }\end{array}$ & Aditi (2014) & $\begin{array}{l}\text { Fontoura e } \\
\text { Fukushima } \\
\text { (2012) }\end{array}$ & $\begin{array}{l}\text { Woloszyn } \\
\text { (2018) }\end{array}$ \\
\hline $\begin{array}{l}\text { Família } \\
\text { tipográfica }\end{array}$ & Fonte legível & $\begin{array}{l}\text { Arial, Verdana } \\
\text { ou Tahoma; } \\
\text { Não utilizar } \\
\text { letras rebuscadas } \\
\text { ou com serifas }\end{array}$ & $\begin{array}{l}\text { Arial e Times } \\
\text { New Roman no } \\
\text { peso regular e } \\
\text { sem inclinação. }\end{array}$ & $\begin{array}{l}\text { Fontes com } \\
\text { desenhos mais } \\
\text { simples, } \\
\text { Fontes } \\
\text { monoespaçadas }\end{array}$ & $\begin{array}{l}\text { Tipos com } \\
\text { proporções } \\
\text { clássicas } \\
\text { romanas, com ou } \\
\text { sem serifa. }\end{array}$ & - \\
\hline $\begin{array}{l}\text { Tamanho } \\
\text { dos textos }\end{array}$ & - & Corpo 24pt & De 18 a 21 pt. & Entre 16 e $18 p t$ & $\begin{array}{l}\text { Adequado às } \\
\text { necessidades do } \\
\text { público. }\end{array}$ & $\begin{array}{l}\text { Tamanhos de } \\
\text { texto maiores do } \\
\text { que os } \\
\text { recomendados } \\
\text { para meios } \\
\text { impressos }\end{array}$ \\
\hline Entrelinha & - & - & $120 \%$ & $\begin{array}{l}25 \text { a } 30 \% \text { maior } \\
\text { que o corpo do } \\
\text { texto }\end{array}$ & $\begin{array}{l}\text { Proporcional ao } \\
\text { tamanho do } \\
\text { corpo e } \\
\text { comprimento da } \\
\text { linha }\end{array}$ & $\begin{array}{l}\text { Requer uma } \\
\text { entrelinha } \\
\text { positiva. }\end{array}$ \\
\hline Entreletras & - & - & Padrão da fonte. & $\begin{array}{l}\text { Maior espaço } \\
\text { entreletras }\end{array}$ & $\begin{array}{l}\text { Que garanta uma } \\
\text { textura } \\
\text { constante no } \\
\text { bloco texto. }\end{array}$ & $\begin{array}{l}\text { Criam } \\
\text { uniformidade } \\
\text { nos textos e } \\
\text { ajudam a } \\
\text { conduzir o leitor } \\
\text { pelo texto }\end{array}$ \\
\hline $\begin{array}{l}\text { Variações } \\
\text { tipográficas }\end{array}$ & - & Usar negrito & Regular & $\begin{array}{l}\text { Escrita em caixa } \\
\text { alta e baixa; } \\
\text { Evitar itálico. }\end{array}$ & $\begin{array}{l}\text { Evitar uso de } \\
\text { caixa alta e usar } \\
\text { o peso e largura } \\
\text { intermediários. }\end{array}$ & $\begin{array}{l}\text { Auxiliam a } \\
\text { conferir } \\
\text { hierarquia ao } \\
\text { conteúdo. }\end{array}$ \\
\hline Cores & $\begin{array}{l}\text { Cores } \\
\text { contrastantes }\end{array}$ & - & $\begin{array}{l}\text { O contraste é } \\
\text { fundamental, } \\
\text { mas deve evitar } \\
\text { cores vibrantes. }\end{array}$ & $\begin{array}{l}\text { Alto contraste } \\
\text { em texto e } \\
\text { fundo; } \\
\text { Cor apenas em } \\
\text { destaques; } \\
\text { Corpo do texto } \\
\text { preto sobre } \\
\text { branco }\end{array}$ & $\begin{array}{l}\text { Atenção ao } \\
\text { contraste entre } \\
\text { figura e fundo ao } \\
\text { usar cores. }\end{array}$ & $\begin{array}{l}\text { Recomenda-se o } \\
\text { uso de contraste } \\
\text { moderado. }\end{array}$ \\
\hline Layout & $\begin{array}{l}\text { Layout em } \\
\text { coluna e } \\
\text { Formatação } \\
\text { adequada dos } \\
\text { parágrafos; } \\
\text { Evitar imagens } \\
\text { de fundo }\end{array}$ & $\begin{array}{l}\text { O número de } \\
\text { caracteres por } \\
\text { linha não deve } \\
\text { ultrapassar } 39 .\end{array}$ & - & $\begin{array}{l}\text { Margens internas } \\
\text { maiores; } \\
\text { Papéis com } \\
\text { acabamentoo } \\
\text { fosco; } \\
\text { Utilizar o } \\
\text { formato para } \\
\text { distinguir } \\
\text { publicações }\end{array}$ & $\begin{array}{l}\text { Entre } 45 \text { e } 65 \\
\text { caracteres por } \\
\text { linha. Dar } \\
\text { preferência ao } \\
\text { alinhamento à } \\
\text { esquerda. }\end{array}$ & $\begin{array}{l}\text { O comprimento } \\
\text { da linha não } \\
\text { deve ser muito } \\
\text { longa. }\end{array}$ \\
\hline Movimento & $\begin{array}{l}\text { Apresentar } \\
\text { conteúdo } \\
\text { estático }\end{array}$ & - & - & - & - & - \\
\hline Adaptação & $\begin{array}{l}\text { Alteração de cor } \\
\text { e tamanho dos } \\
\text { textos; } \\
\text { Visualização } \\
\text { monocromática }\end{array}$ & & & & & \\
\hline \multicolumn{5}{|c|}{ Diretrizes específicas para aplicação da tipografia para usuários de baixa visão } & \multicolumn{2}{|c|}{$\begin{array}{l}\text { Diretrizes gerais de aplicação da tipografia } \\
\text { em meios digitais e favoráveis a legibilidade } \\
\text { e leiturabilidade }\end{array}$} \\
\hline
\end{tabular}


O contraste entre o texto e fundo é citado pela maioria dos autores consultados como fator muito importante para garantir boa legibilidade. Sobre este tema destaca-se a ferramenta online Leserlich, disponibilizada pela Federação Alemã de Pessoas Cegas e com Baixa Visão (DBSV, 2021), retratada na figura 1.

Figura 1: Leserlich Ferramenta online para cálculo de contraste (Fonte: DBSV)
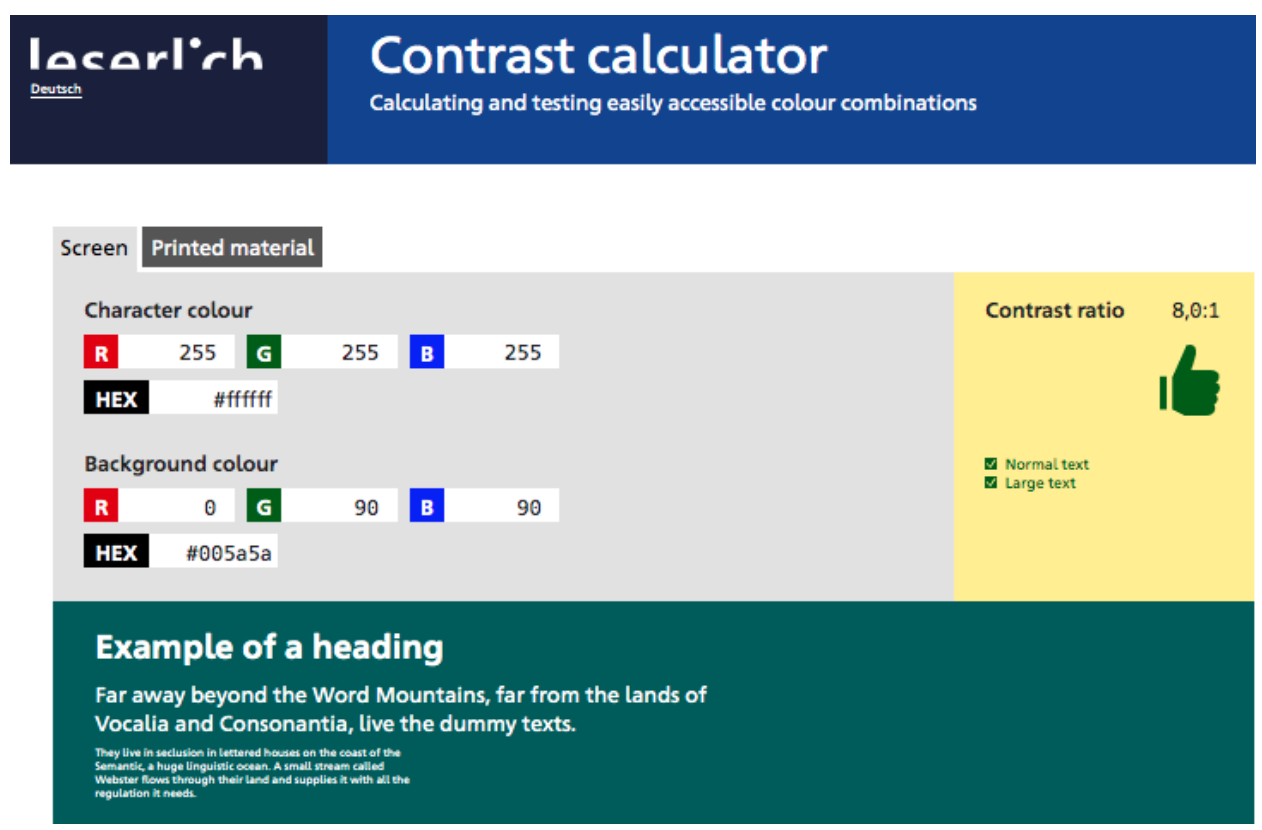

A ferramenta possibilita avaliar a adequação do contraste entre as cores de texto e fundo, tanto no meio impresso quanto digital. O cálculo é feito com base na norma alemã DIN 32975 correlacionando a luminância de duas superfícies.

\section{Procedimentos metodológicos}

A fim de avaliar as diretrizes encontradas na literatura com relação a aplicação da tipografia para usuários de baixa visão, aplicou-se as mesmas no redesenho de uma peça gráfica que foi submetida a leitura de 3 pessoas com baixa visão. Por meio de entrevistas semi-estruturadas, as pesquisadoras questionaram os participantes sobre seu diagnóstico de baixa visão, seus hábitos de leitura no meio digital e sua experiência com as duas versões da peça gráfica, buscando identificar se as mudanças feitas resultaram efetivamente em melhorias na legibilidade e leiturabilidade. A figura 2 ilustra as etapas que compõem os procedimentos metodológicos adotados no presente estudo. 
Figura 2: Etapas realizadas

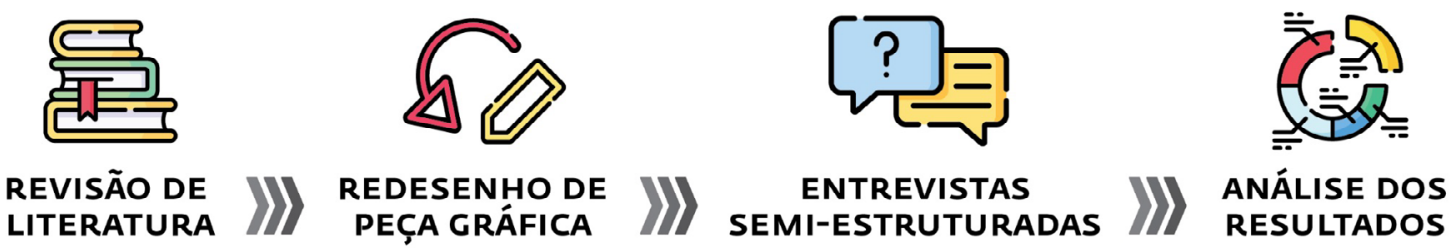

\section{Redesenho da peça gráfica}

O informativo escolhido trata sobre cuidados para evitar a Covid-19. O assunto foi selecionado devido a importância de informações claras e acessíveis a diferentes públicos sobre a doença em questão e buscou-se peças gráficas distribuídas digitalmente por instituições científicas. Foi selecionada uma entre as diversas peças disponíveis no site da Fundação Oswaldo Cruz Fiocruz. Sobre o arquivo disponibilizado no site, é importante observar que se trata de uma imagem em formato JPEG, que mesmo tendo boa resolução apresenta distorções quando ampliada. Além disso, sendo imagem, não pode ser lida por softwares leitores de tela, o que compromete a acessibilidade da peça.

Ao adaptar a peça de acordo com as recomendações do quadro 1 foram realizados os ajustes apresentados na figura 3 e o arquivo foi salvo em formato PDF.

Figura 3: Informativo sobre a Covid-19, peça gráfica original e adaptada

Peça gráfica original
- Família Montserrat

- Fonte de texto em tamanho menor do que o recomendado para o público com baixa visão tendo aproximadamente 17 pts.

- Variações de peso e baixo contraste entre texto e fundo em algumas partes.

- A largura de coluna dentro do recomendado para o público em geral, 45 a 65 caracteres por linha, mas maior do que o recomendado para leitores com baixa visão, 39 caracteres por linha.
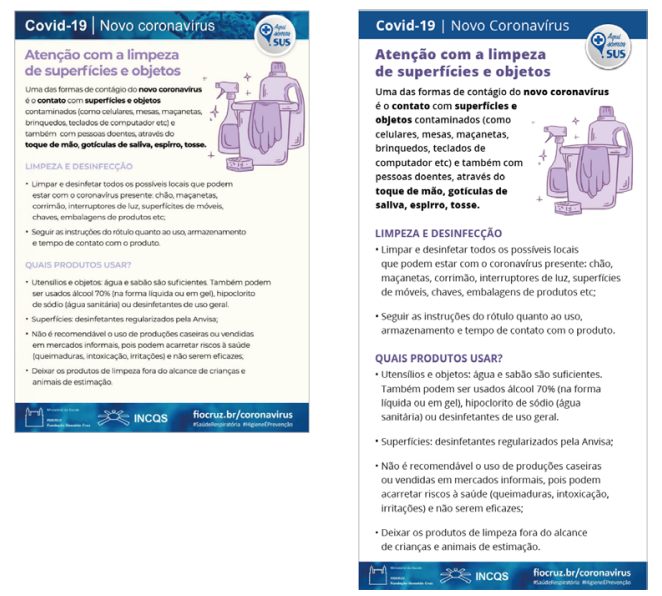

Alterações realizadas

- Família Open Sans

- Tamanho da fonte de texto com 24 pt com entrelinha ajustada para $150 \%$.

- Uso da fonte em diferentes pesos para testar qual seria melhor lido.

- Aumento de contraste das cores no cabeçalho e nos títulos, validado pela ferramenta Leserlich.

- Redução da largura de coluna ficando mais próxima à

recomendada para leitores com baixa visão.

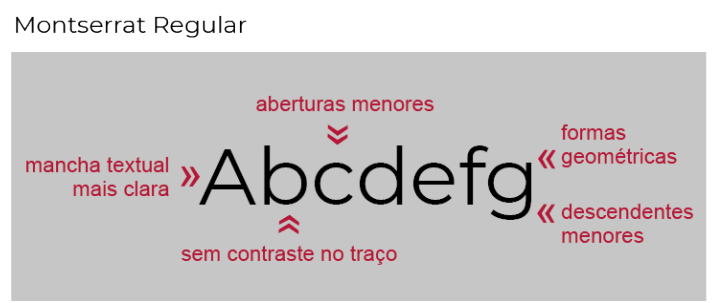

Open Sans Regular

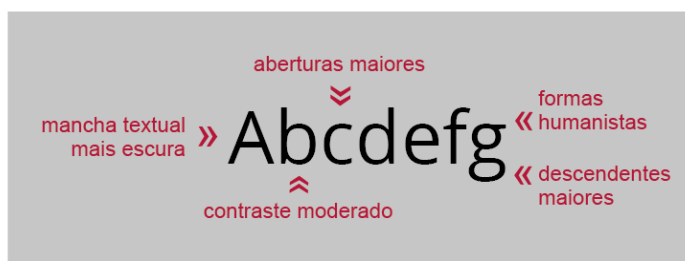




\section{Entrevistas semi-estruturadas}

As entrevistas com o público alvo foram realizadas por videoconferência utilizando a ferramenta Google Meet, de forma individual e tendo duração de aproximadamente 30 minutos. As 2 peças gráficas foram encaminhadas com antecedência para leitura prévia. Durante a entrevista os participantes relataram brevemente seu diagnóstico de baixa visão e seus hábitos de leitura em meio digital para que as pesquisadoras pudessem traçar o perfil, estes dados foram sintetizados no quadro 2 .

Quadro 2: Perfil dos participantes

\begin{tabular}{|c|c|c|c|}
\hline & Participante 1 & Participante 2 & Participante 3 \\
\hline Idade e gênero & 47 anos, feminino & 41 anos, masculino & 19 anos, feminino \\
\hline $\begin{array}{l}\text { Formação e } \\
\text { profissão }\end{array}$ & $\begin{array}{l}\text { Doutora em Inglês - Estudos da } \\
\text { Linguagem. } \\
\text { Atua como } \\
\text { técnicaadministrativa na UFSC. }\end{array}$ & $\begin{array}{l}\text { Formado em Jornalismo. Atua } \\
\text { como técnicoadministrativo na } \\
\text { UFSC. }\end{array}$ & $\begin{array}{l}\text { Estudante, graduanda em } \\
\text { Animação - UFSC. }\end{array}$ \\
\hline $\begin{array}{l}\text { Diagnóstico de } \\
\text { baixa visão }\end{array}$ & $\begin{array}{l}\text { Visão de } 20 / 200 \text { no olho direito } \\
\text { e } 20 / 400 \text { no olho esquerdo, } \\
\text { devido a toxoplasmose } \\
\text { congênita }\end{array}$ & $\begin{array}{l}\text { Lesão na retina devido a } \\
\text { toxoplasmose congênita. Visão } \\
\text { de } 20 / 200 \text { no olho direito e e } \\
20 / 400 \text { no olho esquerdo. }\end{array}$ & $\begin{array}{l}\text { Nistagmo congênito por } \\
\text { traços de albinismo, } \\
\text { astigmatismo, miopia e } \\
\text { hipermetropia. Acuidade } \\
\text { visual olho direito } 20 / 60 \text { e } \\
\text { olho esquerdo } 20 / 40\end{array}$ \\
\hline $\begin{array}{l}\text { Hábitos de leitura } \\
\text { em meio digital }\end{array}$ & $\begin{array}{l}\text { Leitora assídua, principalmente } \\
\text { materiais acadêmicos, em } \\
\text { meios digitais há mais de } 7 \\
\text { anos. }\end{array}$ & $\begin{array}{l}\text { Preferência por materiais } \\
\text { impressos devido a } \\
\text { luminosidade dos dispositivos } \\
\text { digitais. } \\
\text { As leituras em tela se } \\
\text { concentram para textos } \\
\text { pequenos e informações } \\
\text { rápidas. }\end{array}$ & $\begin{array}{l}\text { Leitura assídua em ereader } \\
\text { principalmente para leituras } \\
\text { acadêmicas e textos longos. }\end{array}$ \\
\hline
\end{tabular}

Destaca-se, portanto, que todos os participantes utilizam a leitura em meios digitais nas tarefas relacionadas à sua atuação profissional. Relacionado a isso, pontua-se que duas participantes (01 e 03) são leitoras assíduas em meios digitais principalmente no computador e e-reader, inclusive para textos logos. Já o outro entrevistado cita a leitura em meios digitais apenas para textos curtos e informações rápidas, optando pela leitura de textos longos, o meio impresso.

Com relação ao diagnóstico dos entrevistados, percebe-se que eles possuem níveis distintos de baixa visão. Conforme o Conselho Brasileiro de Oftalmologia (Ottaiano et al., 2019) há sete níveis de severidade de deficiência visual, são eles, leve, moderada, severa, além de 4 níveis de cegueira. De acordo com essa classificação, a participante 01 possui deficiência 
visual severa, o diagnóstico do participante 02 se enquadra em cegueira, enquanto a participante 03 possui deficiência visual moderada.

\section{Análise dos resultados}

As participantes 01 e 03 tiveram dificuldades em ler a peça original na visualização $100 \% \mathrm{e}$ precisaram ampliar os textos para concluir a leitura. Já o Participante 02 mencionou que a peça original parece ter mais informações do que a peça adaptada devido a configuração dos textos. Nesse sentido, os participantes abordaram a dificuldade em ampliar o arquivo em .JPEG, pois os textos ficaram desfocados, impossibilitando a leitura. Com isso, destaca-se também a preferência dos entrevistados pelos materiais de leitura em .PDF tanto pela qualidade quanto pela autonomia possibilitada pelo formato do arquivo.

Sobre a fonte escolhida para a peça adaptada, os participantes concluíram que a mesma é mais confortável do que a fonte utilizada na peça original. Nesse sentido, a participante 03 destaca que o peso mais acentuado da letra influenciou na maior qualidade de leitura. Isso mostra que as indicações para fontes mais simples e com aberturas humanistas são adequadas ao público e auxiliam na leitura por parte dos mesmos, como proposto por Aditi (2014) e Meürer, Gonçalves e Correia (2014). Cabe destacar que a indicação por famílias tradicionais não necessariamente condiciona a leitura apenas à elas, mas sim, fontes contemporâneas que apresentem as características supracitadas também atendem às demandas expostas.

Com relação aos pesos, na peça adaptada, um dos parágrafos foi configurado com peso semi-bold e destaques em extra-bold. Quanto a isso, as participantes 01 e 03 entendem que um pouco mais de peso na letra do corpo de texto torna a leitura mais agradável do que o peso regular utilizado nos demais textos, e que os destaques em extra-bold desta peça estão coerentes, colaborando para estabelecer a hierarquia do conteúdo. Já para o participante 020 conforto dos dois pesos é similar. Isso mostra que tipos levemente mais pesados podem auxiliar na leitura para o público de baixa visão, principalmente os que possuem um diagnóstico de menor acuidade visual. Embora Meürer, Gonçalves, Correia (2014) indiquem o uso do peso regular, é importante considerar que pode haver influência do desenho da letra, quantidade de texto e o meio de reprodução. Ao levar em consideração que a luminosidade dos dispositivos digitais pode tornar as letras imprecisas nesta visualização (Woloszyn, 2018), esta compensação no peso das letras pode ser compreendida como um ajuste às telas digitais.

Embora o corpo de texto em peso semi-bold na peça adaptada tenha sido considerado confortável pelos entrevistados, os três ressaltaram que se o bloco estivesse todo com o peso das palavras destacada (extra-bold), a leitura não teria o mesmo conforto, o que vai no sentido contrário das orientações propostas pelo Instituto Benjamin Constant (2014). Conforme esta referência bibliográfica, os materiais didáticos para público de baixa visão deve ser compostos em negrito. Entretanto, acredita-se que, pela unanimidade na fala dos entrevistados, esta orientação necessita de uma ressalva, e deve considerar também o desenho das letras para tal afirmação. 
Em relação às diferenças de peso aplicadas na peça original, a participante 03 sentiu um desconforto na alta variação entre os pesos do corpo do texto e dos destaques. Isso mostra que é preciso haver um cuidado com os desenhos e variações das letras escolhidas para compor peças acessíveis ou voltadas para o público de baixa visão. Apesar disso, os participantes 01 e 02 relataram que o uso de letras mais pesadas, confere destaque às palavras, indicando hierarquia. Sendo assim, o peso bold e extra-bold usado em ambas as peças cumprem a sua função de evidenciar a organização das informações, conforme exposto na literatura por Woloszyn (2018).

Sobre a composição dos blocos de textos, os três participantes ressaltaram que o tamanho das letras maiores e levemente mais espaçadas na peça adaptada são mais adequadas em decorrência das limitações visuais que possuem. Sobre o tamanho dos textos, cabe destacar que foi possível notar, durante a adaptação da peça, a grande variação entre os tamanhos ocasionado pela altura- $x$ das fontes, que interfere diretamente na proporção das ascendentes $e$ descendentes da fonte. Sobretudo, reforça-se que as orientações de Aditi (2014) e Meürer, Gonçalves e Correia (2014), indicam tamanhos menores do que os aplicados nas peças. Entretanto, por se tratarem de indicações com foco no meio impresso e testadas com público com diferentes níveis de baixa visão, deve-se considerar juntamente às orientações de Woloszyn (2018) que sugerem o uso de tamanhos maiores do que os recomendados para impressos quando em meios digitais.

Ainda em relação à composição dos textos, especificamente sobre o espaçamento entre palavras, compara-se às orientações de Arditi (2014) e Meürer, Gonçalves e Correia (2014). Arditi (2014) propõe palavras mais espaçadas, enquanto Meürer, Gonçalves e Correia (2014) sugerem o espaçamento padrão da fonte. Na peça adaptada, as letras foram levemente mais espaçadas (tracking 5 para os textos e 10 para os títulos) e isto foi percebido e destacado pelos participantes como um fator que favoreceu a leitura. Também destaca-se o espaçamento entrelinhas. Foi aplicada uma entrelinha de $150 \%$ do tamanho da fonte, superior às indicações encontradas nas orientações para materiais voltados ao público em questão. Apesar disso, para os participantes este fator contribuiu no conforto de leitura. Portanto, diante da análise dos espaçamentos, é possível perceber que textos mais arejados, tanto espaçamentos levemente mais abertos entre as letras como as entre as linhas, podem favorecer a visualização de textos por parte do público de baixa visão.

O contraste das cores utilizadas nos títulos das peças também foi citado pelos entrevistados. Para as participantes 01 e 03, o ajuste do contraste da cor roxa na peça adaptada, facilitou a leitura. A participante 03 reforça que a cor utilizada na peça original se confunde com o fundo branco pelo baixo contraste. Para o participante 02 , foi possível ler os títulos em ambos os arquivos, porém o roxo da peça adaptada chamou mais a atenção do mesmo. Desta forma, reforça-se as indicações sobre o uso de cores com bom contraste entre texto e fundo identificado nas referências consultadas (Pinto, Silveira, Teixeira, 2019; Instituto Benjamin Constat, 2014; Meürer, Gonçalves, Correia, 2014; Aditi, 2014) bem como entende-se que a ferramenta Leserlich possibilita uma boa avaliação e adequação das cores. 
Com relação ao cabeçalho das peças, os participantes 02 e 03 disseram não haver interferência na leitura devido à textura utilizada no fundo da peça original. Entretanto, para a participante 01 o cabeçalho com fundo de cor única da peça adaptada se mostrou mais apropriado à leitura. Para Pinto, Silveira e Teixeira (2019), deve-se evitar imagens de fundo em materiais para o público de baixa visão. Porém, como não houve unanimidade na percepção dos leitores consultados, acredita-se que a orientação necessite de uma ressalva com a possibilidade de avaliar os tipos de textura e quantidade de informações visuais presente nas imagens.

\section{Considerações finais}

Com o objetivo de avaliar a eficiência da aplicação das recomendações sobre tipografia para baixa visão em meio digital, este estudo realizou uma entrevista semi-estruturada com este público. Com isso, foi possível avaliar as recomendações encontradas na literatura sobre a aplicação da tipografia voltada para o público de baixa visão.

Em relação aos procedimentos metodológicos adotados é possível enfatizar que as entrevistas à distância possibilitaram o acesso rápido e flexível à voluntários do público em questão. Apesar disso, devido à distância, não foi possível verificar como os entrevistados interagiram com as peças gráficas avaliadas. Apesar dos mesmos terem comentado sobre esta interação, não foi possível observar as primeiras reações às peças, bem como avaliar o tempo levado para a leitura dos textos.

A partir do estudo, percebeu-se que as recomendações apresentadas na revisão bibliográfica se mostraram eficazes, em sua maioria, quando aplicadas na adequação da peça gráfica e apresentadas aos leitores com baixa visão. Porém é importante destacar que existem ressalvas em alguns pontos que se devem, principalmente, a variações entre o impresso e o digital, características do desenho da fonte e ao perfil do leitor. O que reforça a importância não apenas de observar as recomendações, mas também de constante avaliação e preferencialmente envolvendo o público com baixa visão.

Como sugestões para trabalhos futuros, indica-se a adaptação e avaliação de documentos longos e que envolvem outros tipos de leitura além da leitura rápida avaliada no informativo escolhido para este estudo.

\section{Referências}

Arditi, A. (2014). Making text legible: designing for people with partial sight. lighthouse internacional. Disponível em: http://www.lighthouse. org/accessibility/design/accessible-printdesign/making-text-legible/.

DBSV. Leserlich: Calculating and testing easily accessible colour combinations. Disponível em: https://www.leserlich.info/werkzeuge/kontrastrechner/index-en.php. Acesso em: 26 de abril de 2021. 
Frascara, J. (2015). What is information Design? In: FRASCARA, Jorge (Ed.). Information Design as principled action: Making information accesible, relevant, understandable and usable. Illinois: Commom Ground.

Fundação Dorina Nowill para Cegos. (2014). Deficiência visual. Disponível em: http://www.fundacaodorina.org.br/deficiencia- visual/

Instituto Benjamin Constant. (20140. Galeria de imagens. Disponível em: $<$ http://www.ibc.gov.br/?itemid=89>

Kulpa, C. C., Pozzi, M. D. (2010). As Tipografias para usuários de baixa visão nas interfaces computacionais. Encuentro Latinoamericano de Diseño, Buenos Aires.

Kuzu, E. B.; Ceylan, B. (2010). Typographic properties of on line learnig en- vironments for adults. Procedia Social and Behavioral Sciences, v. 9, p. 879-883.

Lemos, A. (2018). Cibercultura e Mobilidade: a Era da Conexão. In: Razón y Palabra Vol. 22.

Meürer, M. V., Gonçalves, B. S., Correia, V. J. B. (2014) TIPOGRAFIA E BAIXA VISÃO: uma discussão sobre a legibilidade. Projética, Londrina, V.5 N.2, p. 33 - 46.

Mengtsung, T.; Chiakai, L.; Zouren, K.; Piyu, C. (2013). A Study of E-Book Readability. Applied Mechanics and Materials, v. 262, p. 227-230.

Ottaiano, J. A. A., Avila, M. P., Umbelino, C. C., Taleb, A. C. (2019) As Condições de Saúde Ocular no Brasil. Conselho Brasileiro de Oftalmologia.

Pamental, Jason. (2014). Responsive Typography: Using Type Well on the Web. Sebastopol: O'Reilly Media.

Pettersson, Rune. (2002). Information Design: an introduction. John Benjamins Publishing Company: Amsterdam/Philadelphia.

Pinto, K. C. B., Silva, R. P., Teixeira, F. G. (2019). Requisitos de projeto de interfaces gráficas de objetos de aprendizagem acessíveis para usuários com baixa visão. Educação Gráfica, v.23, n.1.

Ribeiro, Nuno. (2012). Multimédia e Tecnologias interativas. Lisboa: FCA. Salaveria

Scaglione, J. (2014). Processos e métodos. In: Henestrosa, C.; Meseguer, L.; Scaglione, J. Como criar tipos: do esboço à tela. Brasília: Estereográfica.

Salaverría, R. (2014). Multimedialidade: informar para cinco sentidos. In: CANAVILHAS, J. Webjornalismo: 7 características que marcam a diferença.

Tarasov, D. A.; Sergeev, A. P.; Filimonov, V. V. (2015). Legibility of texto- books: a literature review. Procedia Socia and Behavioral Sciences, v. 174, p.1300-1308.

Trevisan, J. (2012) Design editorial para deficientes visuais. Universidade Tecnológica Federal do Paraná.

Woloszyn, M. (2018). Fatores de aplicação da tipografia em livros digitais. Dissertação (Mestrado). Universidade Federal de Santa Catarina.

\section{Sobre as autoras}

Maíra Woloszyn, Msc., UFSC, Brasil <maira.projetar@gmail.com>

Mary Vonni Meürer, Dra., UFSC, Brasil <mary.meurer@ufsc.br> 